\title{
Imaging of striatal injury in a songbird brain
}

\author{
Kristina Lukacova ${ }^{1}$, Ladislav Baciak ${ }^{2}$, Eva Pavukova ${ }^{1}$, Katarina Pichova $^{1}$, Svatava Kasparova ${ }^{2}$ \\ and Lubica Kubikova ${ }^{1}$ \\ ${ }^{1}$ Department of Physiology and Ethology, Institute of Animal Biochemistry and Genetics, Slovak Academy of Sciences, \\ Ivanka pri Dunaji, Slovakia \\ ${ }^{2}$ Department of NMR spectroscopy and Mass spectroscopy, Faculty of Chemical and Food Technology Slovak University of \\ Technology, Bratislava, Slovakia
}

\begin{abstract}
Neurological insults affect both, brain structure and behavior. The injury-induced brain plasticity and associated changes in behavior are difficult to study using classical histological methods. The magnetic resonance imaging (MRI), however, enables repeated inspection of the brain in the same individual. Here we took advantage of the songbird model with discrete brain circuitry controlling song learning and production and assessed if a conventional MRI is suitable to detect even relatively small brain changes. Our aim was to monitor injury and the following regeneration in the striatal vocal nucleus Area X that controls vocal learning in juveniles and affects song in adult songbird zebra finch (Taeniopygia guttata). The regeneration process was detected using T2-weighted images and validated by immunohistochemical (IHC) staining up to 6 months after the injury. Despite the small volume of the zebra finch brain, a satisfactory signal-to-noise ratio was achieved with reasonably short measurement times. No significant difference was found between the measurements of the lesion size obtained by MRI and IHC staining. Our data show that the non-invasive MRI technique can reliably measure and quantify the regeneration process even in a relatively small part of the brain and that the avian striatum progressively regenerates after its neurotoxic injury.
\end{abstract}

Key words: MRI - Zebra finch brain — Striatum - Neurotoxic lesion - Validation - Immunohistochemical staining

\section{Introduction}

Adult brain shows a remarkable plasticity associated with a recovery from brain injuries, including traumatic brain injury, stroke, or epileptic seizures (Marshall 2000; Felling and Levison 2003; Gopurappilly et al. 2011; Wagner and Zitelli 2013; Westlake and Byl 2013; Rolfe and Sun 2015). Brain injury induces neurogenesis in mammals and birds (Emery et al. 2005; Sun et al. 2007; Zheng et al. 2013; Kubikova et al. 2014). The injury-induced newly generated neurons can integrate into the existing circuitry and are associated with behavioral recovery in rodents and songbirds (Emery et al. 2005; Sun et al. 2007; Kubikova et al. 2014). Although there is an extraordinary therapeutic potential of the brain to repair and regenerate, it

Correspondence to: Lubica Kubikova, Department of Physiology and Ethology, Institute of Animal Biochemistry and Genetics, Slovak Academy of Sciences, Ivanka pri Dunaji, Slovakia E-mail: Lubica.Kubikova@savba.sk is not certain if the injury-induced neurogenesis will be beneficial, i.e. whether the newborn neurons will survive under all circumstances and have a behavioral effect (Yu et al. 2016). Such questions can be answered by MRI method that enables repeated visualization of brain structure and activity.

MRI is a powerful non-invasive technique providing the advantage of longitudinal studies of brain plasticity and lower number of animals in experiments as the same animal can be used to obtain data from several time points after an experimental intervention (Poldrack 2000; Van der Linden et al. 2009; Hamaide et al. 2015). Further, initial evaluation of the extent of brain injury can help to eliminate some animals from further behavioral or physiological experiments. MRI has been widely used in humans, rodents as well as in small animals such as mice and songbirds. Anatomical images can be acquired routinely with $1 \mathrm{~mm}^{3}$ resolution (Hutton et al. 2008) and used to study Huntington's disease, Alzheimer's disease, multiple sclerosis, or brain injury after hypoxic insult (Allegrini and Sauer 1992; Jack et al. 2015; Johnson et al. 
2015; Lin et al. 2015). Neuroanatomical slices can also be prepared with the resolution of $<100 \mu \mathrm{m}$ (Van der Linden et al. 1998). However, brain regions in small animals are subtle such as vocal areas controlling song learning and production. For example, the biggest vocal region in the songbird zebra finch called Area X is about $1 \mathrm{~mm}^{3}$ (Nixdorf-Bergweiler and Bischof 2007) and several slices are necessary to measure its volume. Other vocal nuclei are even smaller. Additionally, degenerative and/or regenerative changes might occur in smaller parts of the brain regions. Therefore it needs to be established if such small changes can be measured by the MRI.

In the past few decades, songbirds have been often used as a neurobiological model to study brain plasticity. They share with humans the rare ability to learn vocalizations and there are behavioral (phases of learning), anatomical (brain circuits, auditory feedback) as well as genetic parallels between human speech and birdsong (Jarvis 2004; Bolhuis et al. 2010). The birdsong is controlled by a discrete system of brain vocal nuclei. They are connected within a motor pathway necessary for vocal production and a cortico-striato-thalamo-cortical loop necessary for vocal learning (Nottebohm et al. 1976; Scharff and Nottebohm 1991). The latter one is an anatomical and functional homolog of the mammalian cortical-basal ganglia-thalamic-cortical loop (Jarvis et al. 2000; Doupe et al. 2005). The basal ganglia component is a striatal nucleus called Area X. It is necessary for the proper song learning in juveniles (Scharff and Nottebohm 1991) and affects song tempo and transition to the next song segment in adults (Kobayashi et al. 2001; Kubikova et al. 2014). Similarly to humans, the striatum including Area X in songbirds recruits significant numbers of newborn cells and neurons in adulthood (Doetsch and Scharff 2001; Ernst et al. 2014; Brenowitz and Larson 2015). Striatal insult using a neurotoxin increases the incorporation of the newborn neurons into the injured region and Area X significantly recovers over a period of a few months (Kubikova et al. 2014). These newborn neurons are the most abundant type, the medium spiny neurons, and the regenerative changes are accompanied with behavioral changes. However, it is not clear if the newborn neurons in the regenerating Area X affect the behavioral changes. Studies that link the brain regeneration with behavior require a repeated inspection of the lesion size that can be correlated with behavioral variation in the same animal.

The aim of our study was to examine brain injury and detect the progressive regeneration including relatively subtle changes in the lesion size using the 3D MRI technique with 4.7 Tesla scanner. We used a small animal model of songbirds with the neurotoxic lesion in the vocal nucleus Area X. The size of the intact nucleus Area X is about $0.9 \times$ $1.0 \times 1.2 \mathrm{~mm}^{3}$, the biggest regeneration occurs within the first month $(\sim 70 \%)$ but it is lower in the later months $(<15 \%)$ (Kubikova et al. 2014). Here we monitored the regeneration of Area X by T2-weighted MRI before and during 6-months period after injection of neurotoxin into Area X and with- out a contrast agent. The lesion size measured by MRI was validated by immunohistochemical staining.

\section{Materials and Methods}

\section{Animals}

We used 17 adult male zebra finches (Taeniopygia guttata) 4-12 months old, weighting $17 \pm 3$ g from our breeding colony. Birds were housed in an aviary with temperature $27 \pm 3^{\circ} \mathrm{C}$, humidity $55 \pm 4 \%$, light:dark cycle $14: 10$, and food, water, grit and cuttlebone available ad libitum. The experiment was approved by the State Veterinary and Food Administration of the Slovak Republic.

\section{Surgery}

We created bilateral neurotoxic lesions of the striatal nucleus Area X by stereotaxic surgery with ibotenic acid ( $1 \%, \mathrm{pH}=7$; Sigma, USA). Birds were under isoflurane inhalation anesthesia (concentration 1-2.5\%; flow 0.8-1 1/min; Nicholas Piramal, USA). We used local anesthetic (Mesocain, Zentiva, SK) before cut a skin and defined zero point as a point where the two hemispheres and cerebellum meet. The coordinates for Area X were 4.5-5.0 mm rostrally, $1.3 \mathrm{~mm}$ laterally, and $3.5 \mathrm{~mm}$ ventrally. To create lesions, we used Nanoject II (Drummond Scientific, USA) to inject $46 \mathrm{nl}$ into each Area $\mathrm{X}$ three times. We were waiting $2 \mathrm{~min}$ between the injections to prevent leakage of the neurotoxin. Birds were recovering under an infrared heating lamp.

\section{MRI scanning}

Brain scans were acquired using a 4.7 Tesla MRI scanner (Agilent, Yarton, GB) equipped with $400 \mathrm{mT} / \mathrm{m}$ gradient insert. A quadrature volume coil transmitter with internal diameter of $72 \mathrm{~mm}$ (Rapid Biomed, Rimpar, Germany) and two-channel anatomically shaped surface coil receiver (STARK Contrast, Erlangen, Germany) were used for signal detection. T2-weighted 3D images were acquired by 3D Fast spin echo sequence with the following parameters: TR/TEeff/ $\mathrm{NEX}=2000 \mathrm{~ms} / 80 \mathrm{~ms} / 1$, echo train length 8 , echo spacing $10 \mathrm{~ms}$, FOV $20 \times 20 \times 20 \mathrm{~mm}$, matrix size $128 \times 128 \times 128$ giving isometric resolution of $156 \mu \mathrm{m}$. The scanning time was $1 \mathrm{~h} 8 \mathrm{~min}$. Each bird was measured before surgery (pre-op) to avoid random injury and to display Area X. The birds were scanned one day (1D), one month (1M), three months (3M) and six months (6M) after the surgery. During the MR scanning, the birds were under isoflurane anesthesia. The initial dose was $2.5 \%$ and the maintenance dose was $1.5-1.7 \%$ of isoflurane, keeping the respiration rate about $50 \mathrm{bpm}$. Temperature in the scanner was maintained at $39^{\circ} \mathrm{C}$ by warm air 
(SA Instruments, Inc.). After each of the post-op scans (1D, $1 \mathrm{M}, 3 \mathrm{M}), 4$ birds were sacrificed by decapitation. After the $6 \mathrm{M}$ scan, 5 birds were sacrificed. The brains were quickly dissected and frozen in Tissue Tec OCT Compound (Sakura, Japan).

\section{Immunohistochemical (IHC) staining}

Embedded brains were cut into $20 \mu \mathrm{m}$ thick coronal slices, mounted on silanated slides and stored at $-20^{\circ} \mathrm{C}$ until IHC staining. First, the brain slices were fixed for $30 \mathrm{~min}$ in $4 \%$ paraformaldehyde at room temperature. Then they were washed three times for $2 \mathrm{~min}$ in $0.1 \mathrm{M}$ phosphate buffered saline (PBS, $\mathrm{pH}=7.4$ ). Nonspecific binding was blocked for $1 \mathrm{~h}$ in a solution containing $1 \%$ bovine serum albumin (BSA; Sigma, USA) and $0.2 \%$ Triton X-100 in PBS. The slices were incubated for $48 \mathrm{~h}$ at $4^{\circ} \mathrm{C}$ with monoclonal mouse primary antibody against the neuronal marker $\mathrm{HuC} / \mathrm{HuD}$ (anti-Hu; Molecular Probes, USA), diluted 1:100 in the blocking solution. The $\mathrm{HuC} / \mathrm{HuD}$ protein is expressed in young but also mature neurons and is widely used to delineate song nuclei (Thompson and Brenowitz 2005; Balthazart and Ball 2014; Kubikova et al. 2014). Subsequently, they were washed three times in PBS for 2 min and incubated with donkey anti-mouse IgG conjugated with Alexa 488 (Molecular probes, USA) for $2 \mathrm{~h}$ at room temperature in the dark. The secondary antibody was diluted 1:250 in the blocking solution. At the end, the slides were washed three times in PBS for 2 min, rinsed in deionized water, and coverslipped with Vectashield mounting medium containing DAPI (Vector Laboratories, USA).

\section{Evaluation of MRI and IHC staining}

Before the image analysis of MRI scans, the data were zero filled to $256 \times 256$ matrix sizes in read and phase encode direction. Down-sampling to 64 was applied in z-direction to increase the contrast to noise ratio. The lesion size was evaluated by the software ImageJ ver1.49 (Schneider et al. 2012). The images containing Area $X$ from IHC staining were acquired using the microscope Leica DM 5500, 2.5× objective, the camera Leica DFC $340 \mathrm{FX}$ and the software Leica microsystems LAS AF 6000. The measurements of Area $\mathrm{X}$ size and lesion size were performed on every fourth slice using the software Adobe Photoshop (Adobe, USA). The lesion size was calculated as a percentage of lesioned Area X post-op per the whole Area X pre-op. Statistical differences were assessed by analysis of variance (ANOVA) followed by Fisher's LSD test.

\section{Results}

We were able to visualize Area $\mathrm{X}$ and its lesion before and after the surgery in the same bird. The vocal nucleus Area X was usually delineated as slightly darker area within the striatum. The lesion always encompassed Area X and showed hyperintense (bright) signal 1 day after the surgery. At the later time points, the lesion showed hypo-intense (dark) signal (Fig. 1).

The size of the whole Area $\mathrm{X}$ before the neurotoxic injury was $1.23 \pm 0.20 \mathrm{~mm}^{3}$ (mean $\left.\pm \mathrm{SEM}\right)$. Although
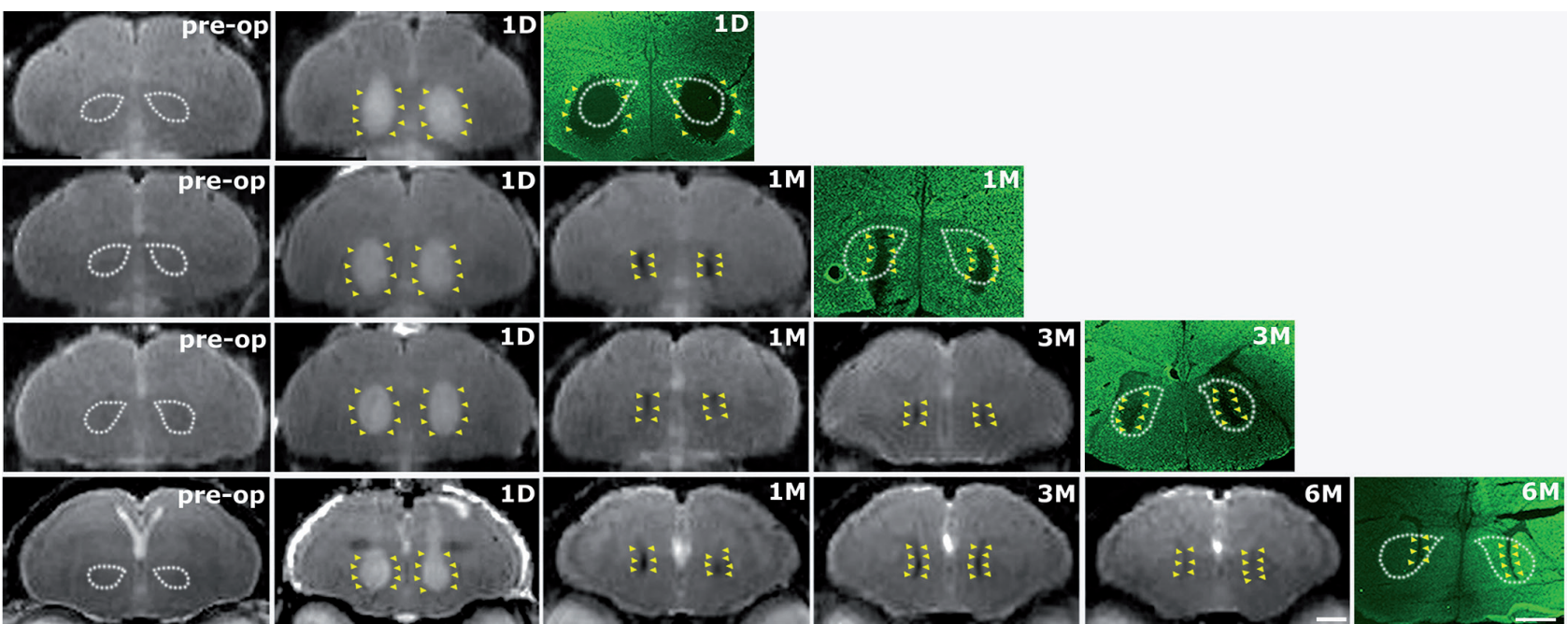

Figure 1. Time course of the lesion development in Area X. Each row shows brain coronal slices in one bird. The first images are from MRI scans and are black and white. The last image in each row is an IHC image from the same animal (neurons containing the marker $\mathrm{Hu}$ are stained with a secondary antibody conjugated with Alexa 488 fluorophore shown green). MRI was performed before surgery (pre-op) and 1 day (1D), 1 month (1M), 3 months (3M), and 6 months (6M) after the surgery. Area X is surrounded by white dashed line in the MRI pre-op image and in the IHC image. Lesions are pointed by arrowheads in the MRI post-op images and in the IHC images. The scales in the last MRI image and in the IHC image represent $1 \mathrm{~mm}$. 
MRI showed that the lesion covered $87.38 \pm 2.47 \%$ (mean \pm SEM; i.e. $1.10 \pm 0.03 \mathrm{~mm}^{3}$ ) of Area X 1 day after the surgery, it decreased significantly to $34.88 \pm 4.13 \%(0.43 \pm$ $\left.0.05 \mathrm{~mm}^{3}\right)$ at 1 month, to $20.22 \pm 1.15 \%\left(0.25 \pm 0.01 \mathrm{~mm}^{3}\right)$ at 3 months, and to $11.94 \pm 1.39 \%\left(0.15 \pm 0.01 \mathrm{~mm}^{3}\right)$ at 6 months (Fig. 2). When we compared these values with the lesion sizes in the same animals obtained by IHC staining, we found that the values measured from the MRI scans and IHC staining images are not significantly different ( $p=0.3-0.9$ for the time points after Area X injury). The size of the whole Area X measured by IHC staining was $1.16 \pm 0.23 \mathrm{~mm}^{3}$

In the last row of Fig. 1, the bird had an enlarged lateral ventricle (shown white in the shape of the letter $\mathrm{V}$ in the middle of the section in the pre-op image, or white in the center between hemispheres in the other images). We observed it in several birds and they did not show any obvious physical impairment or abnormal behavior. The highlighted rim in the next image (1D) appeared only immediately after the surgery and was absorbed later on.

We validated by IHC staining the Area $\mathrm{X}$ lesion size in 4 birds at each post-op time point (1D, 1M, 3M) but there were available the MRI scans also from all of the other birds that survived longer ( 13 surviving birds at $1 \mathrm{D}, 9$ birds at $1 \mathrm{M}$, 5 birds at $3 \mathrm{M}$ ). We compared the validated values from MRI scans with the non-validated values from MRI scans and found that they did not differ significantly $(p=0.4-0.78$ for $1 \mathrm{D}, 1 \mathrm{M}$, and $3 \mathrm{M})$.

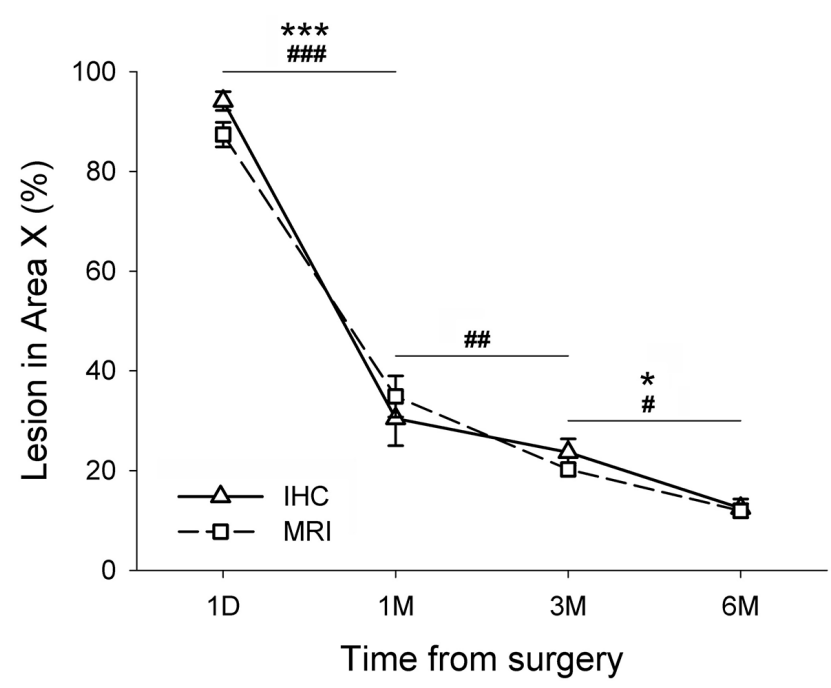

Figure 2. Comparison of lesion size measured by MRI and IHC staining. Each time point represents a mean and SEM $(n=4$ for $1 \mathrm{D}, 1 \mathrm{M}, 3 \mathrm{M} ; n=5$ for $6 \mathrm{M})$. Statistical differences were obtained by ANOVA and Fisher's LSD test. ${ }^{*} p<0.05,{ }^{* * *} p<0.001$ (comparisons of lesion size measured by IHC staining); $\# p<0.05$, \#\# $p<$ $0.01, \# \# p<0.001$ (comparisons of lesion size measured by MRI)

\section{Discussion}

In this study, the non-invasive MRI technique was adapted for repeated in vivo examination of brain insult in small animal species. The lesion size of the nucleus controlling song called Area X was assessed both by MRI and IHC staining in the songbird zebra finch. There were no statistically significant differences between the measurements. Thus, the MRI method has been validated to identify short-term and long-term changes in brain structure up to 6 months after the injury.

Bilateral injections of ibotenic acid provide a model for investigating cognitive dysfunctions in neurodegenerative disorders, stroke, or traumatic brain injury (Schwarcz et al. 1984; Nicotera and Lipton 1999; Eijkenboom et al. 2000) and help to find a function of specific brain areas (Chen et al. 2014). Previous report of longitudinal analysis of neurotoxic lesion development showed a good delineation of the injury in mouse piriform cortex and transient changes related to edema using 4.7 Tesla scanner (Ben-Horin et al. 1996). Here we were able to detect even more subtle changes of striatal lesion recovery at the same magnetic field strength. Songbirds in general dispose of higher level of regeneration after brain injury (Doetsch and Scharff 2002; Peterson et al. 2004; Kaslin et al. 2008; Kubikova et al. 2014). The peak in the regeneration of Area X after neurotoxic injury during the first month is followed by slower regeneration in the next months. These brain changes are accompanied with changes in singing behavior (Scharff and Nottebohm 1991; Scharff et al. 2000; Kubikova et al. 2014). The opportunity of the more detail and repeated in vivo analysis of brain structure will reduce the number of animals needed for experiments and importantly, it will also enable to correlate the MRI findings with behavioral changes in the same animals.

On the other hand, the MRI method also has some limitations. For our study, the biggest restraint was the small size of the brain. The whole zebra finch brain is about $1 \mathrm{~cm}$ long and the size of Area X is only about $0.9 \times 1.0 \times 1.2 \mathrm{~mm}^{3}$ (Nixdorf-Bergweiler and Bischof 2007; Poirier et al. 2008). Then, air cavity causes many artifacts in MRI and birds have pneumatized skull. This can be resolved using spin echo instead of gradient echo sequence, however, at the expense of increasing scan time (Ludwig et al. 2004). Further, the neurologic insult causes edema which covers the extent of injury on the MRI scans. Our T2-weighted images showed hyper-intense signal with traits of edema within the injured area on the first day after injury. This was due to high water content inside the lesion and prolonged $\mathrm{T} 2$ relaxation time in comparison to healthy tissue. The same effect was described in other studies on much larger animals (Bederson et al. 1986; Ben-Horin et al. 1996; Málková et al. 2001). We do not expect that the edema covered a small inefficient lesion 
because immunohistochemical staining showed the lesion of approximately the same size. In our other unpublished experiment, the edema disappeared 5 days after the injury and MRI showed the same lesion size as IHC staining. From 1 month onwards, the lesion changed its appearance to hypo-intense signal, similarly as in other studies (Bederson et al. 1986; Ben-Horin et al. 1996; Málková et al. 2001). Last, there can be a hyper-intense enlarged lateral ventricle and a rim around the brain on the MR image. We observed it in several birds and we do not know the right reason for such visualization. The birds with it did not show any obvious physical impairment or abnormal behavior. The highlighted rim at one day post-lesion is probably a cerebrospinal fluid from the enlarged ventricle. It could be released by the injection into the brain as we observed it in several birds only $1 \mathrm{D}$ after the injection.

We used the $\mathrm{HuC} / \mathrm{HuD}$ antibody as an immunohistochemical marker of neuronal recovery. It is expressed in early postmitotic neurons (Okano and Darnell 1997) and therefore used often as an early marker of neuronal phenotypic differentiation. However, there is a hierarchy in the expression of $\mathrm{Hu}$ RNA binding proteins in developing and adult neurons and $\mathrm{HuC}$ and $\mathrm{HuD}$ can be found in adult neurons in many brain regions in mice (Okano and Darnell 1997). Similarly in songbirds, $\mathrm{Hu}$ is expressed within hours after the division of the neuronal progeny (Barami et al. 1995) but can be expressed also in mature neurons and used to quantify neurons in the brain structures (Haesler et al. 2004; Thompson and Brenowitz 2005; Vellema et al. 2010; Balthazart and Ball 2014; Kubikova et al. 2014). Thus, HuC/ $\mathrm{HuD}$ cannot be used to label only neurons that have become postmitotic recently but is broadly used as a neuronal marker (Balthazart and Ball 2014).

In conclusion, MRI as the non-invasive method provides the advantage of repeated examination of brain injury and/ or its recovery in the same animal. The songbird striatum gradually regenerates after its neurotoxic injury. The MRI cannot replace the detailed IHC staining analysis but it is a beneficial and effective method to define initial and advanced effects of neurotoxin in the brain of small animals.

Acknowledgements. This work was supported by VEGA 2/0177/14 and APVV-15-0077 grants.

\section{References}

Allegrini P. R., Sauer D. (1992): Application of magnetic resonance imaging to the measurement of neurodegeneration in rat brain: MRI data correlate strongly with histology and enzymatic analysis. Magn. Resonan. Imaging 10, 773-778 http://dx.doi.org/10.1016/0730-725X(92)90411-R

Balthazart J., Ball G. F. (2014): Endogenous versus exogenous markers of adult neurogenesis in canaries and other birds: advantages and disadvantages. J. Comp. Neurol. 522, $4100-4120$

http://dx.doi.org/10.1002/cne.23661

Barami K., Iversen K., Furneaux H., Goldman S. A. (1995): Hu protein as an early marker of neuronal phenotypic differentiation by subependymal zone cells of the adult songbird forebrain. J. Neurobiol. 28, 82-101

http://dx.doi.org/10.1002/neu.480280108

Bederson J. B., Bartkowski H. M., Moon K., Halks-Miller M., Nishimura M. C., Brant-Zawadski M., Pitts L. H. (1986): Nuclear magnetic resonance imaging and spectroscopy in experimental brain edema in a rat model. J. Neurosurg. 64, 795-802 http://dx.doi.org/10.3171/jns.1986.64.5.0795

Ben-Horin N., Hazvi S., Bendel P., Schul R. (1996): The ontogeny of a neurotoxic lesion in rat brain revealed by combined MRI and histology. Brain Res. 718, 97-104 http://dx.doi.org/10.1016/0006-8993(96)00058-3

Bolhuis J. J., Okanoya K., Scharff C. (2010): Twitter evolution: converging mechanisms in birdsong and human speech. Nat. Rev. Neurosci. 11, 747-759 http://dx.doi.org/10.1038/nrn2931

Brenowitz E. A., Larson T. A. (2015): Neurogenesis in the adult avian song-control system. Cold Spring Harbor Perspect. Biol. 7, a019000 http://dx.doi.org/10.1101/cshperspect.a019000

Chen J. R., Stepanek L., Doupe A. J. (2014): Differential contributions of basal ganglia and thalamus to song initiation, tempo, and structure. J. Neurophysiol. 111, 248-257 http://dx.doi.org/10.1152/jn.00584.2012

Doetsch F., Scharff C. (2001): Challenges for brain repair: insights from adult neurogenesis in birds and mammals. Brain Behav. Evol. 58, 306-322 http://dx.doi.org/10.1159/000057572

Doetsch F., Scharff C. (2002): Challenges for brain repair: insights from adult neurogenesis in birds and mammals. Brain Behav. Evol. 58, 306-322 http://dx.doi.org/10.1159/000057572

Doupe A. J., Perkel D. J., Reiner A., Stern E. A. (2005): Birdbrains could teach basal ganglia research a new song. Trends Neurosci. 28, 353-363 http://dx.doi.org/10.1016/j.tins.2005.05.005

Eijkenboom M., Blokland A., van der Staay F. J. (2000): Modelling cognitive dysfunctions with bilateral injections of ibotenic acid into the rat entorhinal cortex. Neurosci. 101, 27-39 http://dx.doi.org/10.1016/S0306-4522(00)00342-0

Emery D. L., Fulp C. T., Saatman K. E., Schutz C., Neugebauer E., McIntosh T. K. (2005): Newly born granule cells in the dentate gyrus rapidly extend axons into the hippocampal CA3 region following experimental brain injury. J. Neurotrauma 22, 978-988 http://dx.doi.org/10.1089/neu.2005.22.978

Ernst A., Alkass K., Bernard S., Salehpour M., Perl S., Tisdale J., Possnert G., Druid H., Frisen J. (2014): Neurogenesis in the striatum of the adult human brain. Cell 156, 1072-1083 http://dx.doi.org/10.1016/j.cell.2014.01.044

Felling R. J., Levison S. W. (2003): Enhanced neurogenesis following stroke. J. Neurosci. Res. 73, 277-283 http://dx.doi.org/10.1002/jnr.10670 
Gopurappilly R., Pal R., Mamidi M. K., Dey S., Bhonde R., Das A. K. (2011): Stem cells in stroke repair: current success and future prospects. CNS Neurol. Disord. Drug Targets 10, 741-756 http://dx.doi.org/10.2174/187152711797247894

Haesler S., Wada K., Nshdejan A., Morrisey E. E., Lints T., Jarvis E. D., Scharff C. (2004): FoxP2 expression in avian vocal learners and non-learners. J. Neurosci. 24, 3164-3175 http://dx.doi.org/10.1523/JNEUROSCI.4369-03.2004

Hamaide J., De Groof G., Van der Linden A. (2016): Neuroplasticity and MRI: A perfect match. NeuroImage 131, 13-28 http://dx.doi.org/10.1016/j.neuroimage.2015.08.005

Hutton C., De Vita E., Ashburner J., Deichmann R., Turner R. (2008): Voxel-based cortical thickness measurements in MRI. NeuroImage 40, 1701-1710 http://dx.doi.org/10.1016/j.neuroimage.2008.01.027

Jack C. R., Jr., Barnes J., Bernstein M. A., Borowski B. J., Brewer J., Clegg S., Dale A. M., Carmichael O., Ching C., DeCarli C. et al. (2015): Magnetic resonance imaging in Alzheimer's Disease Neuroimaging Initiative 2. Alzheimer's Dementia 11, 740-756 http://dx.doi.org/10.1016/j.jalz.2015.05.002

Jarvis E. D., Ribeiro S., da Silva M. L., Ventura D., Vielliard J., Mello C. V. (2000): Behaviourally driven gene expression reveals song nuclei in hummingbird brain. Nature 406, 628-632 http://dx.doi.org/10.1038/35020570

Jarvis E. D. (2004): Learned birdsong and the neurobiology of human language. Ann. NY Acad. Sci. 1016, 749-777 http://dx.doi.org/10.1196/annals.1298.038

Johnson E. B., Rees E. M., Labuschagne I., Durr A., Leavitt B. R., Roos R. A., Reilmann R., Johnson H., Hobbs N. Z., Langbehn D. R., Stout J. C., Tabrizi S. J., Scahill R. I. (2015): The impact of occipital lobe cortical thickness on cognitive task performance: An investigation in Huntington's Disease. Neuropsychologia 79, 138-146 http://dx.doi.org/10.1016/j.neuropsychologia.2015.10.033

Kaslin J., Ganz J., Brand M. (2008): Proliferation, neurogenesis and regeneration in the non-mammalian vertebrate brain. Philos. Trans. R. Soc. B 363, 101-122 http://dx.doi.org/10.1098/rstb.2006.2015

Kobayashi K., Uno H., Okanoya K. (2001): Partial lesions in the anterior forebrain pathway affect song production in adult Bengalese finches. Neuroreport 12, 353-358 http://dx.doi.org/10.1097/00001756-200102120-00034

Kubikova L., Bosikova E., Cvikova M., Lukacova K., Scharff C., Jarvis E. D. (2014): Basal ganglia function, stuttering, sequencing, and repair in adult songbirds. Sci. Rep. 4, 6590 http://dx.doi.org/10.1038/srep06590

Lin L., Fu Z., Xu X., Wu S. (2015): Mouse brain magnetic resonance microscopy: Applications in Alzheimer disease. Microsc. Res. Tech. 78, 416-424 http://dx.doi.org/10.1002/jemt.22489

Ludwig R., Bodgdanov G., King J., Allard A., Ferris C.F. (2004): A dual RF resonator system for high-field functional magnetic resonance imaging of small animals. J. Neurosci. Methods $132,125-135$ http://dx.doi.org/10.1016/j.jneumeth.2003.08.017

Málková L., Lex C. K., Mishkin M., Saunders R. C. (2001): MRIbased evaluation of locus and extent of neurotoxic lesions in monkeys. Hippocampus 11, 361-370 http://dx.doi.org/10.1002/hipo.1050

Marshall L. F. (2000): Head injury: recent past, present, and future. Neurosurgery 47, 546-561

Nicotera P., Lipton S. A. (1999): Excitotoxins in neuronal apoptosis and necrosis. J. Cereb. Blood Flow Metab. 19, 583-591 http://dx.doi.org/10.1097/00004647-199906000-00001

Nixdorf-Bergweiler B. E., Bischof H.-J. (2007): A Stereotaxic Atlas of the Brain of the Zebra Finch, Taeniopygia guttata. Bethesda: National Center for Biotechnology Information

Nottebohm F., Stokes T. M., Leonard C. M. (1976): Central control of song in the canary, Serinus canarius. J. Comp. Neurol. 165, $457-486$ http://dx.doi.org/10.1002/cne.901650405

Okano H. J., Darnell R. B. (1997): A hierarchy of Hu RNA binding proteins in developing and adult neurons. J. Neurosci. 17, 3024-3037

Peterson R. S., Lee D. W., Fernando G., Schlinger B. A. (2004): Radial glia express aromatase in the injured zebra finch brain. J. Comp. Neurol. 475, 261-269 http://dx.doi.org/10.1002/cne.20157

Poirier C., Vellema M., Verhoye M., Van Meir V., Wild J. M., Balthazart J., Van Der Linden A. (2008): A three-dimensional MRI atlas of the zebra finch brain in stereotaxic coordinates. NeuroImage 41, 1-6 http://dx.doi.org/10.1016/j.neuroimage.2008.01.069

Poldrack R. A. (2000): Imaging brain plasticity: conceptual and methodological issues - a theoretical review. NeuroImage 12, 1-13 http://dx.doi.org/10.1006/nimg.2000.0596

Rolfe A., Sun D. (2015): Stem cell therapy in brain trauma: implications for repair and regeneration of injured brain in experimental TBI models. In: Brain Neurotrauma: Molecular, Neuropsychological, and Rehabilitation Aspects. (Ed. F. H. Kobeissy), Boca Raton (FL) http://dx.doi.org/10.1201/b18126-49

Scharff C., Nottebohm F. (1991): A comparative study of the behavioral deficits following lesions of various parts of the zebra finch song system: implications for vocal learning. J. Neurosci. 11, 2896-2913

Scharff C., Kirn J. R., Grossman M., Macklis J. D., Nottebohm F. (2000): Targeted neuronal death affects neuronal replacement and vocal behavior in adult songbirds. Neuron 25, 481-492 http://dx.doi.org/10.1016/S0896-6273(00)80910-1

Schneider C. A., Rasband W. S., Eliceiri K. W. (2012): NIH Image to ImageJ: 25 years of image analysis. Nat. Methods $9,671-675$ http://dx.doi.org/10.1038/nmeth.2089

Schwarcz R., Foster A. C., French E. D., Whetsell W. O., Köhler C. (1984): II. Excitotoxic models for neurodegenerative disorders. Life Sci. 35, 19-32 http://dx.doi.org/10.1016/0024-3205(84)90148-6

Sun D., McGinn M. J., Zhou Z., Harvey H. B., Bullock M. R., Colello R. J. (2007): Anatomical integration of newly generated dentate granule neurons following traumatic brain injury in adult rats and its association to cognitive recovery. Exp. Neurol. 204, 264-272

http://dx.doi.org/10.1016/j.expneurol.2006.11.005

Thompson C. K., Brenowitz E. A. (2005): Seasonal change in neuron size and spacing but not neuronal recruitment in a basal 
ganglia nucleus in the avian song control system. J. Comp. Neurol. 481, 276-283

http://dx.doi.org/10.1002/cne.20381

Van der Linden A., Verhoye M., Van Auderkerke J., Peeters R., Eens M., Newman S. W., Smulders T., Balthazart J., DeVoogd T. J. (1998): Non invasive in vivo anatomical studies of the oscine brain by high resolution MRI microscopy. J. Neurosci. Methods 81, 45-52 http://dx.doi.org/10.1016/S0165-0270(98)00013-2

Van der Linden A., Van Meir V., Boumans T., Poirier C., Balthazart J. (2009): MRI in small brains displaying extensive plasticity Trends Neurosci. 32, 257-266 http://dx.doi.org/10.1016/j.tins.2009.01.005

Vellema M., van der Linden A., Gahr M. (2010): Area-specific migration and recruitment of new neurons in the adult songbird brain. J. Comp. Neurol. 518, 1442-1459

http://dx.doi.org/10.1002/cne.22281
Wagner A. K., Zitelli K. T. (2013): A Rehabilomics focused perspective on molecular mechanisms underlying neurological injury, complications, and recovery after severe TBI. Pathophysiology 20, 39-48 http://dx.doi.org/10.1016/j.pathophys.2012.02.007

Westlake K. P., Byl N. N. (2013): Neural plasticity and implications for hand rehabilitation after neurological insult. J. Hand Ther. 26, 87-92 http://dx.doi.org/10.1016/j.jht.2012.12.009

Zheng W., ZhuGe Q., Zhong M., Chen G., Shao B., Wang H., Mao X., Xie L., Jin K. (2013): Neurogenesis in adult human brain after traumatic brain injury. J Neurotrauma 30, 1872-1880 http://dx.doi.org/10.1089/neu.2010.1579

Received: March 16, 2016

Final version accepted: June 13, 2016

First published online: October 27, 2016 